\title{
An evaluation of the maintenance to abstinence (MTA) program in achieving abstinence in opioid users and improving mental health and quality of life
}

\author{
Madeleine M. Southey ${ }^{1}$, Trent Rees ${ }^{2}$, Margaret Rolfe ${ }^{3,4}$ and Sabrina Pit Ti, $^{1,4,5^{*}}$ (1)
}

\begin{abstract}
Background: Residential opioid rehabilitation aims to improve the mental health and quality of life of opioid users through abstinence and residential program participation. This study aimed to determine the depression, anxiety, stress and quality of life amongst maintenance to abstinence (MTA) program residents. Secondary study aims were to assess the personal characteristics of MTA clients, addiction and risk taking behaviours, factors associated with program completion, as well as to assess the reliable change in participants' mental health and quality of life on exit.

Methods: Retrospective analysis of routinely collected data (2013-2017) from surveys completed by 100 clients. Outcome measures were: Depression, Anxiety, Stress Score (DASS-42), World Health Organisation Quality of Life 8 questions (WHOQOL-8) and Kessler Psychological Distress Scale (K10). Other variables included demographics, drug use, other addictions, aggression, self-harm, suicidal ideation/attempts, and risk taking behaviours. Statistical methods included Chi-square, Fisher's exact, t-tests, repeated measures analysis of variance and the Reliable Change Index.

Results: All mean DASS-42, WHOQOL-8 and K10 scores improved significantly in all participants from entry to exit $(p<0.001)$. The majority of participants demonstrated reliable improvement across all psychometric measures. Completion rates for the MTA program were 51\%. Depression $(p=0.023)$, anxiety $(p=0.010)$ and stress $(p=0.015)$ DASS-42 scores decreased significantly more in completers compared to non-completers. The rate of improvement in mean WHOQOL-8 scores and psychological distress scores (K10) was not statistically significantly different between completers and non-completers over time. There was no significant difference between completers and non-completers on socio-demographics, self-reported drug addiction or risk taking behaviour on program entry, except for suicidal thoughts while intoxicated $(p=0.033)$. Completers were more satisfied with their relationships $(p=0.044)$ and living place $(p=0.040)$ on program entry.

Conclusion: Overall, completers and non-completers demonstrated improved mental health and quality of life from entry to exit, regardless of program completion. Depression, anxiety and stress reduced more markedly in program completers. Policy makers and programmers could use these findings to further validate their own programs to improve mental health and quality of life of opioid users.
\end{abstract}

Keywords: Anxiety, Depression, Quality of life, Abstinence, Opioid use, Mental health, Residential rehabilitation, DASS, WHOQOL-8, K10

*Correspondence: s.pit@westernsydney.edu.au

${ }^{1}$ Western Sydney University, Sydney, NSW, Australia

Full list of author information is available at the end of the article

(C) The Author(s) 2019. This article is distributed under the terms of the Creative Commons Attribution 4.0 International License (http://creativecommons.org/licenses/by/4.0/), which permits unrestricted use, distribution, and reproduction in any medium, provided you give appropriate credit to the original author(s) and the source, provide a link to the Creative Commons license, and indicate if changes were made. The Creative Commons Public Domain Dedication waiver (http://creativecommons.org/ publicdomain/zero/1.0/) applies to the data made available in this article, unless otherwise stated. 


\section{Background}

Residential opioid rehabilitation aims to improve the mental health and quality of life of opioid users through participation in a residential program which includes psychological support. A maintenance to abstinence (MTA) program has the specific goal of achieving abstinence from maintenance therapies, also known as opioid agonist medications, such as Methadone or Buprenorphine. Although the standard of care for treatment of opioid use disorder is with maintenance therapies [1], this program offers individuals who would like to wean off these medications the opportunity to do so in a supportive and structured environment. Alternative residential programs for opioid use disorder include the more traditional Therapeutic Community (TC) program which relies on the effects of the socialisation within a group in a residential setting as the main agent of therapy and change [2]. The challenge that individuals with opioid use disorder may face is that some TC programs require abstinence at entry to the program, or may not be equipped to manage and dispense maintenance therapies for those wishing to be included in a residential program who require maintenance therapies [2,3]. The MTA program is similar to a TC program in its residential setting and community focus, however differs in that it provides a dedicated service for those individuals who wish to wean off opioid agonist therapies to achieve abstinence.

\section{The impact of opioid use}

Opioid use impacts the individual's mental health, physical health, social wellbeing and has an impact on Australian society. The negative effects on the individual's mental health are profound [4] with much higher levels of psychological distress and depression experienced by those who use illicit drugs [5-7] with heroin users experiencing the highest rates of mental illness in this group [8]. Substance use disorder is also the most common major comorbidity in those with severe mental illness [9]. Physical health is also impacted with use of illicit drugs contributing to an estimated 2.6\% of Australia's burden of disease, and $0.5 \%$ of deaths in 2010 with major health problems arising from overdose, mental illness, suicide, self-harm, blood borne viruses and death [8]. The selfreported physical health of methadone maintenance patients on entry to a residential rehabilitation program is comparable to that of a person with a severe physical illness [10]. The social impacts include issues of strained family relationships, relationship breakdown and family and intimate partner violence [11]. The impact on Australian society includes increased crime rates, productivity losses and healthcare costs and is estimated to cost the Australian economy $\$ 8$ billion per year $[5,11,12]$.

\section{Maintenance to abstinence programs}

There is an abundance of literature evaluating the utility of different treatment modalities on the mental health and quality of life of opioid users, however there is a gap in the literature for evaluating programs such as the MTA program with a goal of achieving abstinence from maintenance therapies, particularly in Australia.

The UK National Treatment Outcome Research study, a prospective cohort study, studied individuals undergoing treatment for drug addictions in four main treatment modalities (in-patient, residential rehabilitation, methadone reduction and methadone maintenance) [13]. They found that all treatment modalities reduced the frequency of heroin use, non-prescription methadone use, as well as a reduction in injecting and needle sharing in participants over the next 4-5 years of follow up after their stay in a residential rehabilitation program [14]. This study also showed improvements in psychosocial and physical health of participants in any type of treatment for substance use. In a further report of this ongoing study, they found specifically that rates of abstinence were higher in those who attended residential programs and methadone programs. They also found that almost half those who attended the residential rehabilitation treatment were abstinent from heroin 5 years after their treatment [14]. This finding highlights the importance of the residential setting in supporting those with opioid use disorder.

Length of stay has been shown to be a predictor of reliable change in the psychological recovery and wellbeing of individuals after completion of a residential substance use treatment [15] including participation in a therapeutic community. A therapeutic community is a model of residential rehabilitation for substance use in which a group setting provides therapy for its members by engagement in a community and participation in group psychotherapy [16]. A randomised control trial in Iran that found that involvement in a therapeutic community improved the mental health and quality of life of participants to a greater degree than methadone maintenance or residential rehabilitation, however only if the therapeutic community length of stay (LOS) was greater than 6 months [17]. This study found improvements in psychological wellbeing for those receiving any of the three modalities of treatments offered, being therapeutic communities, methadone maintenance, or residential rehabilitation.

The aforementioned programs, similar to the MTA program, have shown improvements in the quality of life and mental health of participants. The high burden of disease and poor psychometric outcomes for opioid users, as well as the social and economic costs to society highlight that there is great need for programs to address 
opioid addiction. Moreover, the availability of residential rehabilitation in those with opioid use disorder is of particular importance as this population is more likely to suffer homelessness and social exclusion limiting their access to outpatient services [11]. This study will contribute to the current available literature through evaluating a residential maintenance to abstinence program in an Australian setting.

This study aimed to primarily determine the depression, anxiety, stress and quality of life levels amongst MTA program residents at program entry and exit. Further aims of this study were to assess the personal characteristics of individuals participating in the Maintenance to Abstinence (MTA) programs and to identify which factors on entry were associated with MTA program completion. The study also aimed to assess the changes in psychometric parameters over time, and evaluate the reliability of the change in these measures between entry and exit of the program.

\section{Method}

This study was a retrospective analysis of routinely collected data from all individuals aged 18 years and over who attended the MTA program between 2013 and 2017 and consented to participating in research evaluation. All participants of the MTA program who consented for this data to be used for research purposes were included in this study.

\section{Research in context}

The maintenance to abstinence program (MTA) is a residential rehabilitation program for individuals with opioid dependence and misuse who aim to achieve abstinence. Entry to the program requires an opioid use history of over 2 years and a personal desire to achieve abstinence, not driven by a condition of bail or other contributing legal pressures.

Individuals attend the program voluntarily and are assisted in reducing, and then achieving abstinence from their maintenance therapy (either Buprenorphine or Methadone) during their stay. Their maintenance medication is then reduced as per the NSW clinical guidelines for the treatment of opioid dependence [18], however they will also meet with a prescriber once per week to review their withdrawal severity, and dose reductions are therefore managed for the individual case.

The program also incorporates psychological support such as counselling and stress management exercises, as well as the opportunity for social engagement through becoming involved in activities, education and low intensity work on site. The aims of these practices are to build self-esteem and reduce mental illness in the residents throughout their rehabilitation. The program also supports the physical health of the residents through regular healthy meal times and encouragement to exercise. The program includes guidance and counselling to teach strategies to cope and remain abstinent after leaving the program [19]. These importance of these psychosocial aspects of the program also follow the NSW clinical guidelines for opioid dependence for those who are achieving abstinence from their maintenance therapies [18].

Participants may leave voluntarily at any point throughout the program, as well as at completion of the program. Upon achieving abstinence, participants may also be given the choice to progress into a therapeutic community program in the same facility. Participants engage with a group and are responsible for domestic tasks, and participate in leisure activities with support from therapists and psychologists. Participants may be asked to leave the program if they are unable to follow the restrictions of substance use in the program, as well as general social and safety requirements of the facility. These participants are considered to have left the program "involuntarily" [19].

\section{Participants and data collection}

Data was routinely collected by staff and through computer based questionnaires. Data was collected on entry to the program, at the halfway point (6 weeks) and on exit of the program (12 weeks, or at the point at which a participant left the program). Participants provided written consent for this data to be used for research purposes. De-identified data was provided to the research team.

Participants were considered to have completed the program if they completed the 91 days in the MTA program, or had achieved abstinence early and progressed to the Therapeutic Community program at the same location.

Ethics approval was given by the University of Western Sydney Human Research Ethics Committee (EC00314), approval number H11353.

\section{Outcome measures}

The primary outcomes measures were quality of life and mental health status of the participants. This involved the use of the psychometric tools the Depression, Anxiety, Stress Scale (DASS) [20], the World Health Organisation Quality of Life scale (WHOQOL-8) [21] and the Kessler Psychological Distress Scale (K10) [22].

The DASS-42 scale measures levels of depression, anxiety and stress as separate subscales Each subscale has a minimum score of zero, maximum score of 42 . A depression score of 0-9 indicates normal levels of depressive symptoms, a score of 10-13 mild, 14-20 moderate, 21-27 severe and over 28 extremely severe depression. 
An anxiety score of 0-7 indicates normal anxiety levels, 8-9 mild, 10-14 moderate, 15-19 severe and over 20 extremely severe anxiety. A stress score of $0-14$ indicates normal stress levels, 15-18 mild, 19-25 moderate, 26-33 severe and over 34 extremely severe stress [23].

WHOQOL-8 is validated for use in Australia [24]. It is a condensed version of the WHOQOL-100 which is specifically adapted for substance use and mental health disorders. It asks questions in eight domains of quality of life with a scoring system of $1-5$, where high scores infer higher satisfaction. The total score of the WHOQOL-8 is the summation of the scores in all eight domains giving a total score of 8-40. The domains are health, energy, money, daily living, self-satisfaction, relationships, living place, and quality of life which reflects the individual's overall perception of quality of life. The score of the WHOQOL-8 reflects an individual's perceived quality of life and was used to assess any change in perceived quality of life over the course of the MTA program.

The Kessler Psychological Distress Score (K10) measures levels of psychological distress. A high K10 score correlates to high levels of psychological distress, and may indicate an increased likelihood of depression or an anxiety disorder. A score under 20 indicates low levels of psychological distress, a score from 20-24 mild levels, 25-29 moderate levels, and over 30 severe levels of psychological distress [25]. The minimum score of the $\mathrm{K} 10$ is 10 , and the maximum 50 . These scores were used to measure mental health at various stages of the MTA program.

The Modified Monash Model (MMM) [26] is a tool used to describe degrees of rurality and remoteness across Australia. It has five categories ranging from MMM1 (Modified Monash Model level 1) indicating an urban centre, with increasing levels of rurality and isolation from an urban centre. MMM5 (Modified Monash Model level 5) refers to regional areas which are not within $10 \mathrm{~km}$ of a town with a population of $5000-15,000$ people.

Further variables that were collected were the participants' age, gender, primary substance of use, age at first use, other addictions, aggression, self-harm and suicidal ideation/attempts, risk taking behaviour and gambling problems.

\section{Statistical analyses}

Descriptive statistics were used to determine the demographics of the cohort, as well as the means of the various outcome measures. Chi-square, Fisher's exact, and t-tests were used to determine the characteristics associated with program completers versus non-completers. A $p$ value of less than 0.05 was considered to be significant. Repeated measures analysis of variance (RMAV), using
SPSS version 24 [27], was used to assess the psychometric measurements (individual DASS-42 and WHOQOL-8 scores and total K10 scores) over time (entry compared to exit) where the time by group (completer/ non-completer) interaction indicates a difference in the rate of change between completers and non-completers over time.

The Reliable Change Index was calculated for the total K10, WHOQOL-8 and DASS-42 scores in line with Turner and Deane [15] and was based on the Christensen and Mendoza formula [28]. It evaluates significant individual change. Participants individual exit and entry scores were subtracted and then divided by the standard error of the difference according to the formula:

$$
R C=\frac{x_{2}-x_{1}}{S_{\text {diff }}}
$$

where $R C=$ relative change, $x_{2}=$ exit scores, $x_{1}=$ entry scores, $S_{\text {diff }}=$ standard error of the difference.

A change score for an individual was considered significant if it was outside the two standard deviations. Participants within the two standard deviations were classified as 'reliably not improved'. Participants on either side of the normal curve of two standard deviations were classified as either 'reliably improved' or 'reliably declined. Each category of reliable change was compared with length of stay in the program. Given the small numbers and the non-normal distribution of length of stay, it was not possible to compare the mean length of stay with each reliable change category. Thus, length of stay was divided into three categories: less than 46 days (1st quartile), 47-82 days (second quartile) and more than 83 days. Following this, a Fisher's exact test was used to determine whether there was an association between reliable change categories and length of stay.

\section{Results}

The inclusion criteria was met by 100 individuals, 14 individuals did not consent to their data being used for research purposes and were therefore excluded from this study.

\section{Completion of program}

Table 1 shows that $51 \%$ of participants completed the program. Of the completers, $23 \%$ completed the full program, and $28 \%$ progressed to the therapeutic community. Fifteen percent left the program voluntarily without completing (Table 1). A minority of participants left the program involuntarily (15\%), 19\% left voluntarily, and 9\% left involuntarily after reducing their maintenance opioid dose. Only $6 \%$ of participants left involuntarily without achieving a reduction in their maintenance opioid dose. 
Table 1 Completion, length of stay, demographic differences and primary drug addiction behaviours in completers versus non-completers

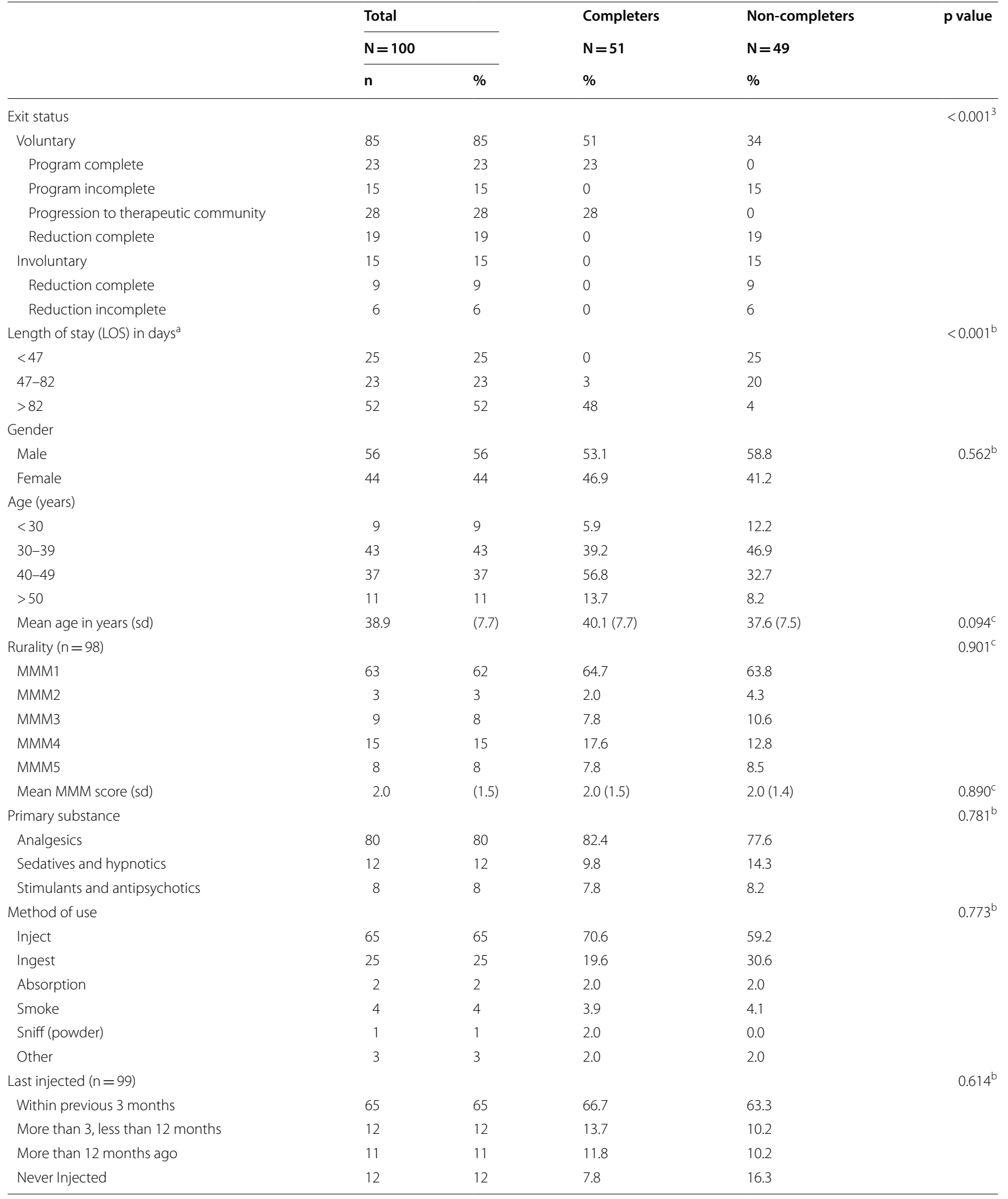


Table 1 (continued)

sd standard deviation, MMM Modified Monash Model

a A completer stay of less than 91 days indicates an early attainment of abstinence and progression to the therapeutic communities program at the same facility

b $\mathrm{p}$ value for Chi-squared test

c $p$ value for t-test

\section{Population sample and drug use behaviour}

The sample population is comprised of $56 \%$ males and $44 \%$ females. The mean age is $38.9(\mathrm{SD}=7.7)$ years, with $80 \%$ of participants aged between 30 and 49 years. The majority of participants (62.4\%) were from a major city [26]. There was no significant difference between completers and non-completers for gender, age, rurality, primary drug addiction behaviour, method of use or last injection (Table 1).

Twelve percent of participants on entry reported nondrug addictions (sex, TV, food, video games, gambling, internet, shopping or exercise), one third reported a problem with aggression and about half reported problems with self-harm or suicidality and 59\% reported risk taking behaviour more than once a month. The only statistically different behaviour between completers and non-completers reported on entry was that a significantly higher number of completers experienced suicidal thoughts while intoxicated $(\mathrm{p}=0.033)$. Most variables had very small numbers (Table 2 ).

\section{Mental health and quality of life in participants}

Table 3 shows that on entry the majority of participants showed moderate to very severe depression (76\%), anxiety (78\%) and stress (63\%). K10 scores showed some missing data throughout, which should be taken into account when interpreting the data. There were no statistically significant differences between completers and non-completers in DASS-42 or K10 entry scores.

WHOQOL- 8 showed only $21 \%$ of participants reporting a "good" quality of life on entry to the program whilst $48 \%$ reported "poor" or "very poor" quality of life (Table 4). Participants scored considerably lower on self-satisfaction with $72 \%$ reporting being either "dissatisfied" or "very dissatisfied". Most quality of life domains on entry showed no significant difference between completers and non-completers, except for living place and relationships. Those who completed the program were less dissatisfied with their relationships with $49 \%$ of completers compared to $65 \%$ of non-completers being either "dissatisfied" or "very dissatisfied" on program entry $(p=0.044)$. Thirty seven percent of completers were either "dissatisfied" or "very dissatisfied" with living place compared to $45 \%$ of non-completers on program entry $(\mathrm{p}=0.040)$.

Table 5 compares completers and non-completers (group) to their change in DASS, WHOQOL-8 and
K10 from entry to exit (time). From the repeated measures ANOVA, all psychometric measures improved significantly over time (entry to exit) for both groups with $\mathrm{p}<0.001$ for all measures. For the time by completion interaction effect, only the three DASS -42 subscales demonstrated significance; depression $(\mathrm{p}=0.023)$, anxiety $(p=0.010)$ and stress $(p=0.015)$. This indicates a significantly faster rate of change between entry and exit for completers compared to non-completers over the duration of the program.

The mean reported depression score at entry is "moderate depression" for completers (20.5) and non-completers (20.2) when scored on the DASS-42 scoring system, the mean on exit is "normal" (7.8) for completers and "mild depression" for non-completers (12.8). Anxiety on entry was "severe" for completers (16.5) and non-completers (16.9), which dropped to "normal" for completers (6.4) and "moderate" for non-completers (12.3) on exit. Stress levels on entry were "moderate" for both completers (20.8) and non-completers (21.5), dropping to "normal" for completers (10.2) and "mild" for non-completers (16.2) on exit. Depression ( $\mathrm{p}=0.023)$, anxiety $(\mathrm{p}=0.010)$ and stress (0.015) scores decreased significantly more for those that completed the MTA program overtime compared to those who did not. Only anxiety $(\mathrm{p}=0.047)$ and stress $(\mathrm{p}=0.018)$ had a significant group (completion) effect indicating that these scores averaged over time were significantly greater in the non-completion group. There was no statistically significant difference on depression, anxiety and stress on entry between completers and non-completers (results not shown).

Completers had higher mean scores for all WHOQOL-8 scores when compared to non-completers on entry and exit. All mean WHOQOL-8 scores improved significantly over time from entry to exit, all with a $\mathrm{p}$ value of $<0.001$ but the rate of improvements were not statistically significantly different between completers and non-completers over time. Only the total quality of life score $(\mathrm{p}=0.010)$ quality of life $(\mathrm{p}=0.017)$, health $(\mathrm{p}=0.023)$, daily living $(\mathrm{p}=0.018)$ and relationships (0.050) had a significant group (completion) effect indicating that these domains averaged over time were significantly higher in the completion group. There was no statistically significant difference on WHOQOL-8 scores on entry between completers and non-completers, with the exception of daily living $(\mathrm{p}=0.042)$ (results not shown). 
Table 2 Self-reported problems in completers versus non-completers on entry

\begin{tabular}{|c|c|c|c|c|c|}
\hline & \multirow{2}{*}{\multicolumn{2}{|c|}{$\begin{array}{l}\text { Total } \\
\mathrm{N}=100\end{array}$}} & \multirow{3}{*}{$\begin{array}{l}\text { Completers } \\
\mathrm{N}=51 \\
\%\end{array}$} & \multirow{3}{*}{$\begin{array}{l}\text { Non-completers } \\
\mathrm{N}=49 \\
\%\end{array}$} & \multirow[t]{3}{*}{$p$ value } \\
\hline & & & & & \\
\hline & $\mathbf{n}$ & $\%$ & & & \\
\hline \multicolumn{6}{|l|}{ General groupings of self-reported problems } \\
\hline Any non-drug addictions & 12 & 12.0 & 11.8 & 12.2 & 0.941 \\
\hline Aggression & 33 & 33.0 & 31.4 & 34.7 & 0.724 \\
\hline Self-harm/suicidality & 52 & 52.0 & 47.1 & 57.1 & 0.313 \\
\hline Risk taking behaviours more than monthly & 59 & 59.0 & 62.7 & 55.1 & 0.437 \\
\hline \multicolumn{6}{|l|}{ Recent self harm and suicidality (in the last 4 weeks) } \\
\hline Thoughts of self-harm & 40 & 39.6 & 33.3 & 46.9 & 0.165 \\
\hline Thoughts of self-harm while intoxicated & 8 & 7.9 & 9.8 & 6.3 & 0.716 \\
\hline Suicidal thoughts & 42 & 41.6 & 39.2 & 44.9 & 0.565 \\
\hline Suicidal thoughts while intoxicated & 11 & 10.9 & 17.6 & 4.2 & 0.033 \\
\hline Self harm attempts & 18 & 17.8 & 15.7 & 20.4 & 0.539 \\
\hline Self harm attempts while intoxicated & 3 & 3.0 & 2.0 & 4.2 & 0.610 \\
\hline Suicide attempts & 19 & 18.8 & 18.0 & 21.3 & 0.684 \\
\hline Suicide attempts while intoxicated & 5 & 5.0 & 5.9 & 4.2 & 1.000 \\
\hline \multicolumn{6}{|l|}{ Current self harm and suicidality on entry } \\
\hline Current self harm behaviour & 1 & 1.0 & 0.0 & 2.0 & 0.490 \\
\hline Current suicide attempts & 1 & 1.0 & 0.0 & 2.0 & 0.490 \\
\hline \multicolumn{6}{|l|}{ Antisocial behaviour } \\
\hline Abusive language & 32 & 31.7 & 31.4 & 32.7 & 0.891 \\
\hline Abusive language while intoxicated & 5 & 5.0 & 3.9 & 6.3 & 0.672 \\
\hline Aggressive behaviour & 8 & 7.9 & 5.9 & 10.2 & 0.483 \\
\hline Aggressive behaviour while intoxicated & 2 & 2.0 & 0.0 & 4.1 & 0.238 \\
\hline Disciplinary action due to aggression behaviour & 1 & 1.0 & 2.0 & 0.0 & 1.00 \\
\hline \multicolumn{6}{|l|}{ Frequency of sharing needles } \\
\hline Monthly or more & 9 & 9.0 & 11.8 & 10.2 & 0.574 \\
\hline Less than monthly & 17 & 17.0 & 21.6 & 12.2 & \\
\hline Once & 25 & 25.0 & 21.6 & 28.6 & \\
\hline Never & 49 & 49.0 & 47.1 & 51.0 & \\
\hline \multicolumn{6}{|l|}{ Frequency of unsafe sex $(n=100)$} \\
\hline Never & 72 & 72.0 & 64.7 & 79.6 & 0.097 \\
\hline Less than monthly/monthly/weekly or more & 28 & 28.0 & 35.3 & 20.4 & \\
\hline
\end{tabular}

$\mathrm{p}$ value for Chi-squared test

Mean K10 scores on entry correlated with "moderate levels of psychological distress" (28.1) for completers and "severe" for non-completers (31.0), which dropped to "none" for completers (19.3) and "mild" for non-completers (23.7) on exit. The K10 score improved significantly over time from entry to exit $(\mathrm{p}<0.001)$ but the rate of improvements were not statistically significantly different between completers and non-completers over time $(\mathrm{p}=0.525)$. K10 scores had a significant group (completion) effect $(\mathrm{p}=0.017)$ indicating that these domains averaged over time were significantly greater in the non-completion group.
There was no statistically significant difference for psychological distress on entry between completers and non-completers.

Table 6 shows that the majority of participants reliably improved on all scores. Length of stay and reliable change scores for the K10, WHOQOL-8 and DASS-42 were not statistically different between the groups. DASS-42 scores improved for $72.8 \%$ of participants, WHOQOL-8 scores reliably improved for $76.3 \%$ of participants, and K10 reliably improved in $74.0 \%$ of participants. The proportion of those individuals that reliably improved was the highest in the longest length of stay (83 days or more) 
Table 3 Mental health entry scores in completers versus non-completers

\begin{tabular}{|c|c|c|c|c|c|}
\hline & \multicolumn{2}{|c|}{ Total } & \multirow{3}{*}{$\begin{array}{l}\text { Completers } \\
\mathrm{N}=51 \\
\%\end{array}$} & \multirow{3}{*}{$\begin{array}{l}\text { Non completers } \\
\mathrm{N}=49 \\
\%\end{array}$} & \multirow[t]{3}{*}{ p value ${ }^{a}$} \\
\hline & \multicolumn{2}{|c|}{$N=100$} & & & \\
\hline & $\mathbf{n}$ & $\%$ & & & \\
\hline \multicolumn{3}{|c|}{ Depression on entry (DASS) } & & & 0.910 \\
\hline Normal-mild & 24 & 24.0 & 23.5 & 24.5 & \\
\hline Moderate-very severe & 76 & 76.0 & 76.5 & 75.5 & \\
\hline \multicolumn{3}{|l|}{ Anxiety on entry (DASS) } & & & 0.390 \\
\hline Normal-mild & 22 & 22.0 & 25.5 & 18.4 & \\
\hline Moderate-very severe & 78 & 78.0 & 74.5 & 81.6 & \\
\hline \multicolumn{3}{|l|}{ Stress on entry (DASS) } & & & 0.718 \\
\hline Normal-mild & 37 & 37.0 & 35.3 & 38.8 & \\
\hline Moderate-very severe & 63 & 63.0 & 64.7 & 61.2 & \\
\hline \multicolumn{3}{|c|}{ Level of psychological distress (K10) on entry ${ }^{b}$} & & & 0.372 \\
\hline None & 13 & 13.5 & 14.3 & 12.8 & \\
\hline Mild & 16 & 16.7 & 18.4 & 14.9 & \\
\hline Moderate & 20 & 20.8 & 26.5 & 14.9 & \\
\hline Severe & 47 & 49.0 & 40.8 & 57.4 & \\
\hline
\end{tabular}

group with $80.8 \%, 78.8 \%$ and $79.6 \%$ reliably improved in the DASS-42, WHOQOL-8 and K10 scores respectively. There was no statistical significance between and increased length of stay and reliable improvement.

\section{Discussion}

\section{Statement of principle findings}

The MTA program appears to improve the mental health and quality of life of those with opioid addiction through involvement in the program, regardless of whether or not they complete the program. Only depression, anxiety and stress reduced more markedly in program completers. Quality of life and psychological distress improved for both completers and non-completers but this improvement was not significantly higher among completers. Reliable improvement was shown across all parameters for the majority of participants, with $74 \%$ showing reliable improvement in $\mathrm{K} 10$ score, $76.3 \%$ showing reliable improvement in WHOQOL-8 score and $72.8 \%$ showing reliable improvement in overall DASS-42 score. This data strengthens the notion that an MTA program is effective in improving mental health and quality of life in opioid users. Factors measured on entry that were associated with completion were suicidal thoughts while intoxicated and the participant's satisfaction with their relationships and living place. This information could be used to develop strategies around improving these measures, or monitoring those who scored lower in these measures which are associated with non-completion.

\section{Meaning of the study}

Improvements in mental health and quality of life should be expected when an individual is supported to remain abstinent from opioid drugs, as the relationship between the use of these substances and poor mental health and quality of life measurements is clearly documented [4, $5,9]$. The results of this study support this body of evidence as improvements in mental health and quality of life parameters were seen among the majority of participants in the program to some degree regardless of completing the program in its entirety. However, completers had significantly greater improvements in their depression, anxiety and stress scores than non-completers. This shows that the program when followed through to completion is associated with better mental health outcomes than partial participation in the program. The quality of life domains improved for both groups but the improvements were not higher in the completion group. It is possible that the individual quality of life domains measured through one question only are not strong enough indicators on their own. The total WHOQOL-8 score was trending towards significance $(\mathrm{p}=0.077)$. The fact that the K10 scores were not significantly different between completers and non-completers may be a reflection of 
Table 4 Quality of life as measured by WHOQOL-8 on entry in completers versus non-completers

\begin{tabular}{|c|c|c|c|c|c|}
\hline & Total & & Completers & Non-completers & p value $^{\mathrm{a}}$ \\
\hline & $N=1$ & & $N=51$ & $\mathrm{~N}=49$ & \\
\hline & $\mathrm{n}$ & $\%$ & $\%$ & $\%$ & \\
\hline WHOQOL-8 on entry & & & & & \\
\hline Overall perception of quality of life & & & & & \\
\hline Very poor & 12 & 12 & 5.9 & 18.4 & 0.131 \\
\hline Poor & 36 & 36 & 35.3 & 36.7 & \\
\hline Neither poor nor good & 31 & 31 & 39.2 & 22.4 & \\
\hline Good/very good & 21 & 21 & 19.6 & 22.4 & \\
\hline Overall perception of health & & & & & \\
\hline Very dissatisfied & 24 & 24 & 17.6 & 30.6 & 0.363 \\
\hline Dissatisfied & 40 & 40 & 43.1 & 36.7 & \\
\hline Neither satisfied nor dissatisfied & 24 & 24 & 23.5 & 24.5 & \\
\hline Satisfied/very satisfied & 12.0 & 12 & 15.7 & 8.2 & \\
\hline Enough energy for daily life & & & & & \\
\hline Not at all & 21 & 21 & 21.6 & 20.4 & 0.422 \\
\hline A little & 32 & 32 & 25.5 & 38.8 & \\
\hline Moderately & 29 & 29 & 35.3 & 22.4 & \\
\hline Mostly & 17 & 17 & 15.7 & 18.4 & \\
\hline Completely & 1 & 1 & 2.0 & 0.0 & \\
\hline Enough money for daily needs & & & & & \\
\hline Not at all & 20 & 20 & 15.7 & 24.5 & 0.260 \\
\hline A little & 37 & 37 & 39.2 & 34.7 & \\
\hline Moderately & 17 & 17 & 23.5 & 10.2 & \\
\hline Mostly & 21 & 21 & 15.7 & 26.5 & \\
\hline Completely & 5 & 5 & 5.9 & 4.1 & \\
\hline Daily living & & & & & \\
\hline Very dissatisfied & 21 & 21 & 15.7 & 26.5 & 0.251 \\
\hline Dissatisfied & 32 & 32 & 27.5 & 36.7 & \\
\hline Neither satisfied nor dissatisfied & 20 & 20 & 21.6 & 18.4 & \\
\hline Satisfied & 23 & 23 & 31.4 & 14.3 & \\
\hline Very satisfied & 4 & 4 & 3.9 & 4.1 & \\
\hline Self-satisfaction & & & & & \\
\hline Very dissatisfied & 25 & 25 & 23.5 & 26.5 & 0.556 \\
\hline Dissatisfied & 47 & 47 & 43.1 & 51.0 & \\
\hline Nether satisfied nor dissatisfied & 16 & 16 & 19.6 & 12.2 & \\
\hline Satisfied & 11 & 11 & 13.7 & 8.2 & \\
\hline Very satisfied & 1 & 1 & 0.0 & 2.0 & \\
\hline Relationships & & & & & \\
\hline Very dissatisfied & 21 & 21 & 11.8 & 30.6 & 0.044 \\
\hline Dissatisfied & 36 & 36 & 37.3 & 34.7 & \\
\hline Neither satisfied nor dissatisfied & 24 & 24 & 29.4 & 18.4 & \\
\hline Satisfied & 14 & 14 & 19.6 & 8.2 & \\
\hline Very satisfied & 5 & 5 & 2.0 & 8.2 & \\
\hline Living place & & & & & \\
\hline Very dissatisfied & 18 & 18 & 11.8 & 24.5 & 0.040 \\
\hline Dissatisfied & 23 & 23 & 25.5 & 20.4 & \\
\hline Neither satisfied nor dissatisfied & 22 & 22 & 25.5 & 18.4 & \\
\hline Satisfied & 26 & 26 & 33.3 & 18.4 & \\
\hline Very satisfied & 11 & 11 & 3.9 & 18.4 & \\
\hline
\end{tabular}


Table 4 (continued)

WHOQOL-8 World Health Organisation Quality of Life 8 Questions

${ }^{a} \mathrm{p}$ value for Chi-squared test

Table 5 Comparison between completers and non-completers (group) on change in DASS, WHOQOL-8 and K10 from entry to exit (time)

\begin{tabular}{|c|c|c|c|c|c|c|c|c|c|c|c|c|c|}
\hline & \multicolumn{2}{|l|}{ Completers } & \multicolumn{2}{|c|}{ Non-completers } & \multicolumn{3}{|c|}{ Time effect } & \multicolumn{3}{|c|}{ Completion effect } & \multicolumn{3}{|c|}{$\begin{array}{l}\text { Time * completion } \\
\text { effect }\end{array}$} \\
\hline & Entry & Exit & Entry & Exit & DF & $\mathrm{F}$ & $\mathbf{P}$ & DF & $F$ & $\mathbf{P}$ & DF & $F$ & $\mathbf{P}$ \\
\hline & Mean (SD) & Mean (SD) & Mean (SD) & Mean (SD) & & & & & & & & & \\
\hline \multicolumn{14}{|l|}{ DASS } \\
\hline Depression & $20.5(8.61)$ & $7.8(6.30)$ & $20.2(10.01)$ & $12.8(10.42)$ & $(1,90)$ & 82.37 & $<0.001$ & $(1,90)$ & 2.51 & 0.117 & $(1,90)$ & 5.35 & 0.023 \\
\hline Anxiety & $16.5(8.97)$ & $6.4(5.49)$ & $16.9(10.77)$ & $12.3(9.94)$ & $(1,90)$ & 51.64 & $<0.001$ & $(1,90)$ & 4.05 & 0.047 & $(1,90)$ & 7.02 & 0.010 \\
\hline Stress & $20.8(7.64)$ & $10.2(6.91)$ & $21.5(9.23)$ & $16.2(9.92)$ & $(1,90)$ & 54.66 & $<0.001$ & $(1,90)$ & 5.81 & 0.018 & $(1,90)$ & 6.12 & 0.015 \\
\hline \multicolumn{14}{|l|}{ WHOQOL-8 } \\
\hline Total score & $20.8(5.68)$ & $29.3(5.69)$ & $19.2(6.67)$ & $24.9(8.57)$ & $(1,91)$ & 80.42 & $<0.001$ & (1.91) & 6.88 & 0.010 & $(1,91)$ & 3.27 & 0.074 \\
\hline Quality & $1.7(0.85)$ & $2.9(0.84)$ & $1.6(1.03)$ & $2.3(1.16)$ & $(1,90)$ & 55.87 & $<0.001$ & $(1.90)$ & 5.96 & 0.017 & $(1,90)$ & 3.25 & 0.075 \\
\hline Health & $1.4(0.96)$ & $2.6(0.92)$ & $1.1(0.95)$ & $2.1(1.15)$ & $(1,90)$ & 73.58 & $<0.001$ & $(1,90)$ & 5.35 & 0.023 & $(1,90)$ & 1.10 & 0.298 \\
\hline Energy & $1.5(1.07)$ & $2.4(0.94)$ & $1.4(1.05)$ & $1.9(1.26)$ & $(1,90)$ & 30.49 & $<0.001$ & $(1,90)$ & 3.08 & 0.083 & $(1,90)$ & 2.49 & 0.118 \\
\hline Money & $1.6(1.12)$ & $2.5(1.15)$ & $1.5(1.21)$ & $2.0(1.33)$ & $(1,90)$ & 26.15 & $<0.001$ & $(1,90)$ & 1.47 & 0.229 & $(1,90)$ & 1.55 & 0.216 \\
\hline Daily living & $1.8(1.17)$ & $2.7(0.92)$ & $1.4(1.14)$ & $2.3(1.14)$ & $(1,90)$ & 37.06 & $<0.001$ & $(1,90)$ & 5.84 & 0.018 & $(1,90)$ & 0.01 & 0.935 \\
\hline Self-satisfaction & $1.2(0.97)$ & $2.6(0.98)$ & $1.1(0.87)$ & $2.1(1.28)$ & $(1,90)$ & 81.20 & $<0.001$ & $(1,90)$ & 3.26 & 0.074 & $(1,90)$ & 2.32 & 0.131 \\
\hline Relationships & $1.6(1.00)$ & $2.6(0.90)$ & $1.3(1.21)$ & $2.2(1.17)$ & $(1,90)$ & 52.19 & $<0.001$ & $(1,90)$ & 3.94 & 0.050 & $(1,90)$ & 0.16 & 0.692 \\
\hline Living place & $1.9(1.11)$ & $3.0(0.79)$ & $1.8(1.50)$ & $2.6(1.22)$ & $(1,90)$ & 39.33 & $<0.001$ & $(1,90)$ & 1.71 & 0.194 & $(1,90)$ & 1.12 & 0.292 \\
\hline \multicolumn{14}{|l|}{$\mathrm{K} 10^{\mathrm{a}}$} \\
\hline Total score & $28.1(8.00)$ & $19.3(5.91)$ & $31.0(8.43)$ & 23.7 (8.84) & $(1,70)$ & 44.30 & $<0.001$ & $(1,70)$ & 6.03 & 0.017 & $(1,70)$ & 0.41 & 0.525 \\
\hline
\end{tabular}

Significant data points are highlighted using italic typeface (significant $P$ values)

$D F$ degrees of freedom (variance), $F \mathrm{~F}$ ratio, $P \mathrm{p}$ value for $\mathrm{F}$ test

${ }^{a} \mathrm{~K} 10$ date is missing 5 responses from entry and 28 responses from exit

the high amount of missing data in this outcome measure $(16 \%)$.

An interesting finding of the study was the association between completion, and less dissatisfaction with living place and relationships according to the WHOQOL-8 score on entry to the program when comparing the level of satisfaction. Living place and relationships have been described as "fundamental human needs" since psychologist Maslow first coined the phrase in 1943 [29]. Living place is of particular concern when supporting those recovering from opioid addiction as there is increased prevalence of unstable housing and homelessness in this population $[11,30]$. This may be another reason that residential settings have been shown to be effective in this population, and important in considering the availability of residential options for opioid use disorder treatment. The fact that only these two quality of life domains measured on entry into the program were associated with completion rates may indicate the importance of living place and relationships in promoting recovery in opioid users. This supports the notion that opioid rehabilitation needs to include social support as well as the involvement of social workers to address the needs of individuals, including practical needs around their living place. It is important to note that due to multiple comparisons the findings can be type 1 error findings and thus maybe due to chance. Additionally, our sample size was relatively small which may have limited our ability to find statistically significant differences between completers and non-completers. It may therefore be useful to re-evaluate these factors when the facilities client base has grown over time.

Another statistically significant association with completers was higher incidence of suicidal thoughts while intoxicated in the 4 weeks before entry to the program. No other self-harm, suicidality while sober, or other risk taking behaviour was associated with completion. It may be of interest to look at an association with levels of alcohol consumption between the two groups to see if this result may be explained by levels of alcohol intoxication. 
Table 6 Proportion of participants classified as reliably improved, not improved or declined on K10, total WHOQOL-8 and total DASS-42 scores and differences in length of stay (days) between groups $(\mathrm{N}=93)$

\begin{tabular}{|c|c|c|c|c|}
\hline \multicolumn{5}{|l|}{ Total sample } \\
\hline Measure & $\%$ Reliably improved (n) & $\%$ Not improved (n) & $\%$ Reliably declined (n) & $p$ value \\
\hline DASS-42 (N=92) & $72.8(67)$ & 19.6(18) & $7.6(7)$ & \\
\hline WHOQOL-8 $(\mathrm{N}=93)$ & $76.3(71)$ & $12.9(12)$ & 10.8(10) & \\
\hline $\mathrm{K} 10(\mathrm{~N}=73)$ & $74.0(54)$ & $13.7(10)$ & $12.3(9)$ & \\
\hline \multicolumn{5}{|l|}{ Length of stay (days) } \\
\hline \multicolumn{5}{|l|}{ DASS-42 $(N=92)$} \\
\hline$\leq 46$ days & $71.4(15)$ & $23.8(5)$ & $4.8(1)$ & 0.088 \\
\hline $47-82$ & $52.6(10)$ & $26.3(5)$ & $21.1(4)$ & \\
\hline $83+$ & $80.8(42)$ & $15.4(8)$ & $3.8(2)$ & \\
\hline \multicolumn{5}{|l|}{ WHOQOL-8 $(\mathrm{N}=93)$} \\
\hline$\leq 46$ days & $72.7(16)$ & $13.6(3)$ & $13.6(3)$ & 0.937 \\
\hline $47-82$ & $73.7(14)$ & $15.8(3)$ & $10.5(2)$ & \\
\hline $83+$ & $78.8(41)$ & $11.5(6)$ & $9.6(5)$ & \\
\hline \multicolumn{5}{|l|}{ K10 Scores $(N=73)$} \\
\hline$\leq 46$ days & $58.3(7)$ & $33.3(4)$ & $8.3(1)$ & 0.158 \\
\hline $47-82$ & $66.7(8)$ & $8.3(1)$ & $25(3)$ & \\
\hline $83+$ & $79.6(39)$ & $10.2(5)$ & $10.2(5)$ & \\
\hline
\end{tabular}

$\mathrm{p}$ value for Fisher's Exact Test for comparisons between groups on length of stay in days

This finding may be due to chance considering that there were no other associations found.

Quality of life and mental health significantly improved over time (entry to exit) for both completers and noncompleters (Table 5). This demonstrates that the program has significant benefit even without continuing to completion. It may be that the opportunity and exposure to psychological therapies in the program leads to improvements in mental health and quality of life even with an earlier exit time. The psychological support offered in the MTA program is evidence based in improving mental health outcomes in individuals suffering substance use disorders [31-33]. The fact that the rate of improvement was better in the completers group when looking at the time by completion interaction effect may indicate that the exposure to psychological interventions for the entirety of the program supports a better rate of improvement in depression, anxiety and stress. This is an important finding for a residential rehabilitation program as it validates their methods throughout the program, showing improved outcomes even amongst those that do not finish the program. There was no significantly different improvement rates in completers K10 scores when looking at the time, completion interaction. Given that $\mathrm{K} 10$ is also a measure of mental health outcomes this is a surprising finding considering the significantly better rates of improvement in the DASS-42 parameters for completers. An explanation for this may be that the missing data in $\mathrm{K} 10$ exit scores gave too small a sample size for a true analysis of rate of improvement in psychological distress.

Reliable improvement was seen across all outcome measures for the majority of participants, strengthening the conclusions of this study. Individuals who remained in the program for more than 83 days had a higher proportion of individuals who showed reliable improvement across all measures. The majority of people who stayed less than 46 days also showed reliable improvements. Increased length of stay was not found to be a statistically significant indicator of improved mental health and quality of life outcomes for participants. Those with the longest length of stay (more than 83 days) having the highest proportion of reliable improvement across all measures may give some support to the current literature which indicates that increased length of stay, particularly of 90 days or more, relates to higher rates of reliable improvement [15], however, the association was not significant in our study. With increased numbers of participants finishing the program in the future it may be of value to repeat this analysis with a larger sample size.

\section{Limitations and strengths}

Study limitations were the small sample size, selfreported data and relatively high missing data for some variables, especially the K10 data. The MTA program data was only available over a four year period, which led to the small sample size for this study and may therefore have been underpowered to detect differences between 
completers and non-completers. Another limitation is that this study does not draw comparison to other treatment modalities such as individuals remaining on maintenance therapies, nor those in a therapeutic community program. Furthermore, the study took place in one particular setting so may not be generalisable to other settings.

\section{Relation to other studies}

The findings of this study support the body of literature which discusses the utility of residential rehabilitation for opioid users on improving their psychosocial wellbeing $[14,15]$. The association between increased mean length of stay in residential substance use treatment, and reliable improvement over all outcome measures supports the findings of Turner and Deane [15].

A study was conducted on the Therapeutic Community program at the same location [34]. Completion rates for this program were lower, however the program itself is significantly longer (217 days as opposed to 98 ). The DASS-42 and WHOQOL-8 scores for participants in this study were however similarly significantly improved. This results of this study with regard to predictors of completion differed, and included age and high WHOQOL-8 scores in the domain of money, which were not found to be significant in this study. It is noted that the sample size for that study was larger $(n=257)$.

\section{Future research}

Future research for both the Buttery's MTA program, as well as other residential opioid rehabilitation programs, would be to conduct long term follow up studies. It would be of interest to examine the same outcome measures of mental health and quality of life at intervals after exit from the program. A survey detailing relapse of opioid or other drug use would be of interest to determine whether abstinence is maintained long term in those who completed the program. Further studies of MTA programs could aim to compare the characteristics of individuals with different dose reduction regimens, as well as withdrawal effect profiles.

\section{Impact of research outcomes}

This study adds to the evidence supporting the use of MTA programs such as The Buttery's. It validates residential MTA rehabilitation as a means of intervention for those affected by opioid use, even if they do not complete the full program. Another potential impact from this study may be that MTA programs continue to improve the mental health and quality of life outcomes for those suffering from opioid use. This may subsequently reduce the impact that these individuals may have on other health services later.
This study may assist rehabilitation program providers to further improve their understanding of the needs of individuals throughout their recovery. In particular, it points to the important and basic needs of individuals to have satisfactory relationships and living arrangements in order to best support their recovery. This may give them a greater chance of program completion. This finding could be used to help identify individuals who are at risk of program drop out, and potentially lower their risk by focussing on improving their satisfaction with both their living place and relationships.

The MTA program in particular are incorporating the findings of this study into practice. Specifically they are reviewing the need for flexibility in length of stay, as well as developing a profile of the significant associations with completion, in order to reflect on how better to meet the needs of the client group who exit the program early.

In conclusion, the use of the MTA program shows reliable improvements in opioid users' mental health and quality of life, irrespective of program completion. Depression, anxiety and stress show increased rates of improvements amongst those that complete the program. These findings may help guide decisions about service requirements for people who are recovering from drug misuse and support the continued use of residential opioid rehabilitation programs.

\section{Abbreviations}

ANOVA: analyses of variance; DASS-42: Depression, Anxiety, Stress Score; K10: Kessler Psychological Distress Scale; LOS: length of stay; MMM: Modified Monash Model; MTA: maintenance to abstinence; STD: standard deviation; WHOQOL-8: World Health Organisation Quality of Life 8 questions.

\section{Authors' contributions}

SWP, TR and MS designed the study. MS with SWP analysed the data with advise from MR. MS drafted the manuscript. SWP, TR and MR provided overall methodological and content expertise guidance. SWP led the study. All authors contributed to revising of the manuscript and have read and approved the final manuscript.

\section{Author details}

${ }^{1}$ Western Sydney University, Sydney, NSW, Australia. ${ }^{2}$ The Buttery, Binna Burra, QLD, Australia. ${ }^{3}$ University of Sydney, Sydney, NSW, Australia. ${ }^{4}$ University Centre for Rural Health, 62 Uralba Street, PO Box 3074, Lismore, NSW 2480, Australia. ${ }^{5}$ Western Sydney University School of Medicine, Campbelltown, NSW, Australia.

\section{Acknowledgements}

We thank all the participants and the John Shaw Warnock Research Grant donor.

\section{Competing interests}

Mr. Rees is Program Manager at the Buttery, Australia. Data analyses was conducted independently from Mr. Rees. No further conflict of interest is declared.

\section{Availability of data and materials}

Datasets which were generated and analysed for this study are not publicly available as the data is confidential. The data sets are available from the corresponding author on reasonable request. 
Consent for publication

Not applicable.

\section{Ethics approval and consent to participate}

Ethics approval was given by the University of Western Sydney Human Research Ethics Committee (EC00314), approval number H11353. Clients who have given written consent to research were included in the study.

\section{Funding}

This project was partially funded by the John Shaw Warnock Research Grant via the Buttery.

\section{Appendices}

\section{Modified Monash Model}

MMM1: Major cities.

MMM2: Regional but within $20 \mathrm{~km}$ of a town with a population over 50,000.

MMM3: Regional that are within $15 \mathrm{~km}$ road distance to a town of population 15,000-50,000.

MMM4: Regional and are in $10 \mathrm{~km}$ road distance from a town with a population of between 5000 and 15,000 .

MMM5: Regional and not within $10 \mathrm{~km}$ distance of a town of population 5000-15,000.

Table legend:

DASS-42 categorical legend [21]:

\begin{tabular}{llclll}
\hline & Normal & Mild & Moderate & Severe & Very severe \\
\hline Depression & $0-9$ & $10-13$ & $14-20$ & $21-27$ & $28-42$ \\
Anxiety & $0-7$ & $8-9$ & $10-14$ & $15-19$ & $20-42$ \\
Stress & $0-14$ & $15-18$ & $15-25$ & $26-33$ & $34-42$ \\
\hline
\end{tabular}

K10 categorical legend [22]:

\section{K10 Score (total) Level of psychological distress}

10-19 The score indicates that the client or patient may currently not be experiencing significant feelings of distress

20-24 The client or patient may be experiencing mild levels of distress consistent with a diagnosis of a mild depression and/or anxiety disorder

30-50 The client or patient may be experiencing severe levels of distress consistent with a diagnosis of a severe depression and/or anxiety disorder

\section{Publisher's Note}

Springer Nature remains neutral with regard to jurisdictional claims in published maps and institutional affiliations.

Received: 6 September 2018 Accepted: 11 January 2019 Published online: 04 February 2019
References

1. Bruneau J, Ahamad K, Goyer MÈ, Poulin G, Selby P, Fischer B, Wild TC, Wood E, CIHR Canadian Research Initiative in Substance Misuse. Management of opioid use disorders: a national clinical practice guideline. CMAJ. 2018;190(9):E247-57.

2. Chen T, Masson CL, Sorensen JL, Greenberg B. Residential treatment modifications: adjunctive services to accommodate clients on methadone. Am J Drug Alcohol Abuse. 2009;35(2):91-4.

3. Sorensen JL, Andrews S, Delucchi KL, Greenberg B, Guydish J, Masson CL, Shopshire M. Methadone patients in the therapeutic community: a test of equivalency. Drug Alcohol Depend. 2008;100(1-2):100-6.

4. Nunes E, Sullivan M, Levin F. Treatment of depression in patients with opiate dependence. Biol Psychiatry. 2004;56(10):7938802.

5. AlHW: Australian Institute of Health and Welfare. National Drug Strategy Household Survey detailed report: 2013. Drug statistics series no. 28. Cat. no. PHE 183. Canberra: AlHW; 2014.

6. Johnson M, Neal D, Brems C, Fisher D. Depression among out-of-treatment injecting drug users as measured by the Beck Depression Inventory 82. Assessment. 2006;13(2):168-77.

7. Magidson J, Gorka S, MacPherson L, Hopko D, Blanco C, Lejuez C, Daughters $S$. Examining the effect of the life enhancement treatment for substance use (LETS ACT) on residential substance abuse treatment retention. Addict Behav. 2011;36(6):6158623.

8. Teesson M, Havard A, Fairbairn S, Ross J, Lynskey M, Darke S. Depression among entrants to treatment for heroin dependence in the Australian Treatment Outcome Study (ATOS): prevalence, correlates and treatment seeking. Drug Alcohol Depend. 2005;78:309-15.

9. Brunette M, Mueser K, Drake R. A review of research on residential programs for people with severe mental illness and co-occuring substance use disorders. Drug Alcohol Rev. 2004;23:471-81.

10. Williamson A, Darke S, Ross J, Teesson M. Changes and predictors of change in the physical health status of heroin users over 24 months. Addiction. 2009;104(3):465-70. https://doi.org/10.111 1/j.1360-0443.2008.02475.x.

11. NRHA: National Rural Health Alliance. Illicit drug use in rural Australia. Fact sheet 33, June 2012. Canberra; 2012. http://ruralhealth.org.au/sites/defau It/files/publications/fact8sheet8338illicit8drug8use8rural8 australia.pdf.

12. Collins D, Lapsley $\mathrm{H}$. The costs of tobacco, alcohol and illicit drug abuse to Australian society in 2004/2005. National Drug Strategy Monograph series no. 66. Commonwealth Department of Health and Ageing, Canberra; 2008.

13. Gossop M, Marsden J, Stewart D, Kidd T. The National Treatment Outcome Research Study (NTORS): 4-5 year follow-up results. Addiction. 2003;98(3):291-303.

14. Gossop M. The National Treatment Outcomes Research Study (NTORS) and its influence on addiction treatment policy in the United Kingdom. Addiction. 2015:110:50-3.

15. Turner B, Deane FP. Length of stay as a predictor of reliable change in psychological recovery and well-being following residential substance abuse treatment. Ther Communities. 2016;37(3):112-20.

16. De Leon G. The therapeutic community: theory, model, and method. New York: Springer; 2000.

17. Babaie E, Razeghi N. Comparing the effects of methadone maintenance treatment, therapeutic community, and residential rehabilitation on quality of life and mental health of drug addicts. Addict Health. 2013;5:16-20.

18. NSW Ministry of Health. NSW clinical guidelines: treatment of opioid dependence; 2018.

19. The Buttery. The Buttery Rehab NSW|Rehab Sydney Brisbane|Rehabilitation Services; 2016. http://www.buttery.org.au.

20. Lovibond S, Lovibond P. Manual for the Depression Anxiety Stress Scales. 2nd ed. Sydney: Psychology Foundation; 1995.

21. WHO QoL: Measuring Quality of Life. Programme on mental health; 1997. http://www.who.int/mental_health/media/68.pdf.

22. Kessler R, Andrews G, Colpe L, Hiripi E, Mroczek D, Normand S, Zaslavsky A. Short screening scales to monitor population prevalences and trends in non-specific psychological distress. Psychol Med. 2002;32(06):959-76.

23. Crawford J, Henry J. The Depression Anxiety Stress Scales (DASS): Normative data and latent structure in a large non-clinical sample. Br J Clin Psychol. 2003;2003(42):111-31. 
24. Network of Alcohol and other drugs agencies (NADA). Using the Client Outcomes Management System (COMS), Network of alcohol and other drugs agencies, Strawberry Hills, Australia; 2012.

25. Australian Bureau of Statistics. 4817.0.55.001 — Information paper: use of the Kessler Psychological Distress Scale in ABS Health Surveys, Australia, 2007-08; 2007.http://www.abs.gov.au/ausstats/abs@.nsf/looku p/4817.0.55.001Chapter92007-08.

26. Australian Government Department of Health. Doctor connect: rural classification reform, Modified Monash Model_frequently asked questions; 2006. http://www.doctorconnect.gov.au/internet/otd/publishing.nsf/ content/classification-changes.

27. IBM Corp. (Released 2016). IBM SPSS Statistics for Windows, Version 24.0. Armonk: IBM Corp.

28. Christensen L, Mendoza J. A method of assessing change in a single subject: an alteration of the RC index. Behav Ther. 1986;12:305-8.

29. Maslow A. A theory of human motivation. Psychol Rev. 1943;50(4):37096. https://doi.org/10.1037/h0054346.
30. Palepu A, Marshall B, Lai C, Wood E, Kerr T. Addiction treatment and stable housing among a cohort of injection drug users. PLoS ONE. 2010;5(7):e11697. https://doi.org/10.1371/journal.pone.0011697.

31. McHugh R, Hearon B, Otto M. Cognitive-behavioral therapy for substance use disorders. Psychiatr Clin N Am. 2010;33(3):511-25. https://doi. org/10.1016/j.psc.2010.04.012.

32. NSW Department of Health. NSW health drug and alcohol psychosocial interventions professional practice guidelines; 2008.

33. Moore B, Fiellin D, Cutter C, Buono F, Barry D, Fiellin L, O'Connor P, Schottenfeld R. Cognitive behavioral therapy improves treatment outcomes for prescription opioid users in primary care buprenorphine treatment. J Subst Abuse Treat. 2016;71:54-7. https://doi.org/10.1016/j. jsat.2016.08.016.

34. Harley M, Pit S, Rees T, Thomas S. Completion Rates and psychosocial intervention effectiveness in an Australian substance abuse therapeutic community. Subst Abuse Treat Prev Policy. 2017;13:33.
Ready to submit your research? Choose BMC and benefit from:

- fast, convenient online submission

- thorough peer review by experienced researchers in your field

- rapid publication on acceptance

- support for research data, including large and complex data types

- gold Open Access which fosters wider collaboration and increased citations

- maximum visibility for your research: over $100 \mathrm{M}$ website views per year

At BMC, research is always in progress.

Learn more biomedcentral.com/submissions 